\title{
Los heraldos del Centauro. La prensa villista de la Ciudad de México (1914-1915)
}

\author{
The Centaur's heralds. The Villista Press of Mexico \\ City (I9I4-I9I5)
}

Francisco Iván Méndez Lara*

* Facultad de Filosofía y Letras de la Universidad Nacional Autónoma de México. Es licenciado, maestro y doctor en Historia por la UNAM. Ha colaborado en diversos proyectos de investigación en El Colegio de México, en el Instituto de Investigaciones Históricas y en el Instituto de Investigaciones Sociales de la UNAM. Es autor de más de una docena de capítulos y artículos especializados. Entre sus últimas publicaciones se encuentran: "La candidatura silenciosa. La campaña presidencial del general Pablo González Garza en las elecciones de 1920, una mirada desde la prensa (2019) y Génesis y primeros años de la Secretaría de Industria, Comercio y Trabajo en México (1917-1920) (2020). Correo electrónico: ivan.mendez.lara@gmail.com

https://orcid.org/0000-0002-4981-3040

Historial editorial

Recibido: 23-febrero-202I

Aceptado: 02-mayo-202I

Publicado: 30-julio-202I

ISSN-e: 2594-2956 
Los heraldos del Centauro. La prensa villista de la Ciudad de México (1914-1915

\section{Resumen}

Francisco Villa y el villismo han sido temas de innumerables libros $y$ artículos especializados, no obstante, el análisis de los periódicos que se crearon para apoyar al caudillo y a su propuesta revolucionaria es escaso. La historiografía ha prestado particular atención al desarrollo de la prensa carrancista, desde la publicación del Plan de Guadalupe hasta el triunfo sobre los ejércitos convencionistas y al monopolio de la información que consolidó Venustiano Carranza entre 1916 y 1919. De forma paralela, existieron distintos proyectos periodísticos que surgieron al calor de la lucha de facciones, entre ellos el de la prensa favorable al villismo, en la Ciudad de México, de agosto de I9I4 a julio de 1915. Este artículo analiza, con base en fuentes hemerográficas, la aparición de un conjunto de periódicos partidarios de la Convención con opiniones favorables al villismo, así como su paulatina descomposición, que terminó con su total desaparición 184 dras las derro

Palabras Clave: Revolución
mexicana, Francisco Villa,
periódicos, lucha de facciones,
Convención revolucionaria.

The Centaur's heralds. The Villista Press of Mexico City (1914-1915)

\section{Abstract}

Francisco Villa and villismo have been the subjects of innumerable books and specialized articles, however, the analysis of the newspapers that were created to support the caudillo and his revolutionary proposal is scarce. Historiography has paid particular attention to the development of the Carranza press from the publication of the Plan of Guadalupe to the triumph over the conventionist armies and the monopoly of information that Venustiano Carranza consolidated between I9I6 and 1919. In parallel, there were different journalistic projects that emerged in the heat of factional struggle, among them that of the provillismo press in Mexico City from August I9I4 to July 1915. This article analyzes, based on hemerographic sources, the appearance of a set of newspapers in favor of the Convention with opinions favorable to Villismo, as well as its gradual decomposition that ended with its total disappearance after the political and military defeats of Villismo.

Keywords: Mexican Revolution, Francisco Villa, newspapers, Faction Struggle, Revolutionary Convention. 
Les hérauts du Centauro. La presse villiste de Mexico (1914-1915)

\section{Résumé:}

Francisco Villa et le villisme ont fait l'objet d'innombrables livres et articles spécialisés, mais l'analyse des journaux qui ont été créés pour soutenir le chef de guerre et sa proposition révolutionnaire est rare. L'historiographie a porté une attention particulière au développement de la presse carranciste depuis la publication du Plan de Guadalupe jusqu'au triomphe sur les armées de convention et au monopole de l'information que consolida Venustiano Carranza entre 1916 et I9I9. Parallèlement, plusieurs projets journalistiques ont vu le jour à la suite de luttes de factions, dont celui de la presse pro-villisme à Mexico d'août I9I4 à juillet I9I5. Cet article analyse, sur la base de sources hématographiques, l'apparition d'un ensemble de journaux partisans de la Convention ayant des opinions favorables au villisme, ainsi que sa décomposition progressive qui se termina par sa disparition totale après les défaites politiques et militaires du villisme.

Mots-clés: Révolution mexicaine, Francisco Villa, Journaux, Lutte des factions, Convention révolutionnaire.
Opiewcy Centaura. Prasa villista w miescie Meksyku (1914-1915)

\section{Streszczenie:}

Francisco Villa i villismo były przedmiotem niezliczonych książek i artykułów specjalistycznych, jednak analiza gazet, które zostały stworzone w celu wsparcia caudillo i jego rewolucyjna propozycja jest ograniczona. Historiografia zwróciła szczególną uwagę na rozwój prasy caranzista od publikacji Planu de Guadalupe do triumfu nad armiami opozycji i monopolu informacji, które Venustiano Carranza skonsolidował w latach I9I6-I9I9. Równolegle pojawiły się różne projekty dziennikarskie, które powstały w ogniu walki frakcji, wśród nich prasa sprzyjająca villismo w Meksyku od sierpnia I9I4 do lipca I9I5 roku. Ten artykuł analizuje na podstawie źródeł hemerograficznych pojawienie się prasy opinujacej na rzecz Konwencji korzystnymi dla villismo, a także jej stopniowym rozkładem, który zakończył się jej całkowitym zniknięciem po politycznych i wojskowych porażkach villismo.

Słowa kluczowe: Rewolucja meksykańska, Francisco Villa, gazety, walka frakcji, Konwencja Rewolucyjna. 


\section{Introducción}

Francisco Villa no consolidó una prensa fuerte que lo apoyara entre I9I3 y 19I6. Esa ha sido la sentencia común entre los principales estudiosos del villismo y de los periódicos revolucionarios, ¿qué tan precisa es esta interpretación? Este artículo muestra una explicación distinta sobre la prensa villista, específicamente la que se creó y difundió en la capital del país, después de la ruptura revolucionaria entre carrancistas y convencionistas.

En principio, se debe destacar la historiografía que ha abordado la prensa revolucionaria. Un libro y un artículo que ofrecen panoramas generales son El periodismo en México: 500 años de historia de Luis Reed Torres y María del Carmen Ruiz Castañeda (2002) y "El historiador y el periodismo mexicano" de Stanley Ross (1965). Durante muchos años fueron los únicos trabajos con los que contábamos para entender la década revolucionaria y su vínculo con la prensa. Fue hasta la década de los noventa del siglo pasado cuando la historiografía sobre la prensa revolucionaria tuvo avances sustanciosos. Deben subrayarse un par de síntesis relevantes del periodo, de la autoría de Álvaro Matute (1995) y Javier Garciadiego (1995). No obstante, estos trabajos apenas si hacen mención de la prensa villista entre I9I3 y I9I5; contrario a esto, los periódicos maderistas y carrancistas son los que cuentan con mayores referencias en libros clásicos de la Revolución mexicana y estudios particulares del periodo I913-I9I5 (Zuaste, I992; Ramírez, 20IO; Méndez, 20I4a, 20I4b y 20I5; Quirvan, 2019).

El vínculo de Villa y la prensa han sido estudiados de forma tangencial por varios autores. Entre ellos deben destacarse el análisis general de Katz (2000) sobre los usos que el villismo dio a la prensa como arma de propaganda, así como los estudios de las representaciones de Villa que la prensa mexicana (carrancista) y la estadounidense llevaron a cabo entre 1913 y 1916 (Anderson, 2000; Méndez, 2020). La prensa de la Convención revolucionaria ha sido estudiada por distintos autores, pero la tendencia villista no ha 
recibido la atención específica que requiere para lograr su cabal comprensión (Ramírez, 2008 y 20I0; Méndez, 2015).

Por ello, debido a la inexistencia de estudios particulares sobre la prensa que apoyó a Villa y al villismo, entre I9I4 y I9I5, el objetivo de este artículo es analizar la trayectoria de los periódicos favorables al villismo, creados en la Ciudad de México en el contexto de la lucha de facciones. Para su desarrollo se utilizaron la hemerografía villista, donde deben destacarse los órganos informativos La Convención, El Monitor, El Combate y El Norte; los últimos dos diarios mencionados apenas si han sido revisados por algunos historiadores. Se parte del supuesto que la prensa favorable al villismo fue mucho más relevante en el contexto de la lucha de facciones de lo que la historiografía ha señalado hasta ahora. Los periódicos villistas publicados en la Ciudad de México tuvieron una estructura editorial bien definida, que entró en crisis debido al desarrollo de la propia guerra.

Este trabajo está dividido en tres apartados. El primero revisa, a grandes rasgos, el vínculo de Villa con la prensa durante la lucha contra el general Victoriano Huerta, periodo en el que los principales diarios fueron Vida Nueva y el Periódico Oficial de Chihuahua, y culmina con la ruptura revolucionaria después del triunfo frente al ejército federal. El segundo analiza la aparición de diarios adictos al villismo en la capital del país, sus objetivos y transformaciones de finales de I9I4 a marzo de I9I5; momento en que existió un fuerte vínculo periodístico entre los villistas y zapatistas. Finalmente, en el tercero, se explica la ruptura periodística de la Convención y la desaparición de sus órganos informativos.

Se considera fundamental revisitar y reinterpretar la historia de la prensa villista; es, sin duda, una deuda historiográfica. Desde nuestro punto de vista resulta "improbable" análizar la prensa sin entrelazarla con la historia política del periodo, ya que "mientras la prensa hacía política, la política hacía prensa, por lo que resultaría imposible analizar a una desligada de la otra" (Alonso, 20I5, p. II). De ahí que en todo momento se vincule el contexto con lo difundido en los periódicos. 
Hace algunos años todavía se cuestionaba un trabajo realizado con mayor cantidad de fuentes hemerográficas porque se decía que la prensa:

[...] está amasada en prejuicios personales del comentarista o redactor, o bien el periódico mismo, que expresa entonces los intereses políticos o económicos de un grupo. En cambio -se piensa -el documento es una verdad fehaciente y, por tanto ofrece una base segura, inconmovible, para la interpretación o el relato histórico, debiera ser innecesario advertir que el documento, al igual que el artículo de una periódico, es un escrito que necesaria, inevitablemente, refleja los sentimientos, las ideas y los intereses de su autor (Cosío, I972, p. 945).

Daniel Cosío Villegas, quien realizó sus tomos de la Historia Moderna de México principalmente con fuentes, invitó a la reflexión del trabajo histórico y a la objetividad y utilidad de las fuentes. Se condiera que el análisis de la fuente hemerográfica puede abrir nuevos derroteros interpretativos, a partir de su estudio es posible entender la conformación del acontecer de una época, así como la manera en que lo narrado en ese momento fue retomado, tiempo después, para legitimar distintos proyectos políticos.

\section{Villa y la prensa antes de la fractura revolucionaria}

La creación de una prensa leal al movimiento villista encontró su génesis a finales de 1913, poco después de la conformación, en septiembre de dicho año, de la División del Norte. El gobierno del estado, ya en manos de los hombres de Villa, comenzó a imprimir en la capital el Periódico Oficial del Estado de Chihuahua y Vida Nueva. Ambos se editaron en la imprenta de Silvestre Terrazas. El Periódico Oficial publicaba los decretos del gobierno villista en Chihuahua y, en ocasiones, algunos editoriales de corte ideológico. Entre los autores 
que participaron destacó el poeta José Santos Chocano (Katz, 2000, p. 479).

Vida Nueva se encargó de ofrecer noticias sobre la lucha contra Huerta, "descripciones detalladas de las batallas, entrevistas con los generales, semblanzas de los dirigentes revolucionarios, constantes elogios a Villa como uno de los mayores generales de la historia, ataques contra Huerta, notas sobre el apoyo estadounidense a la revolución y, muy rara vez, definiciones ideológicas sobre los objetivos de la revolución" (Katz, 200o, p. 479). Las noticias locales que se difundieron en este periódico fueron pocas y no se detuvieron en realizar análisis ideológicos de la Revolución, pero cuando llegaba a publicarse algo al respecto, casi siempre estaba vinculado con la cuestión agraria. El principal contenido de Vida Nueva era propagandístico y tenía como meta exaltar los atributos revolucionarios de Villa; en pocas palabras, quería crear un líder nacional. Entre sus principales directores y colaboradores estuvieron Manuel Bauche Alcalde, José María Hinojosa, Francisco Lagos Cházaro y Juan B. Rosales.

A pesar de contar con estos dos diarios, y algunas hojas sueltas que circulaban en Chihuahua, la prensa villista nunca logró monopolizar la información en su región -entre I9I3 y I9I4- ya que en el estado circulaban periódicos estadounidenses de ciudades como El Paso, Texas, que contenían una sección en español y era leída por los oriundos del estado que tenían esta posibilidad. Por ello, era posible ver en las páginas de Vida Nueva algunos editoriales de periódicos estadounidenses o respuestas a notas o editoriales publicados en $E l$ Paso Morning Times. No obstante, como lo mencionó Katz "no está claro hasta qué punto un diario podía influir en un estado en que la gran mayoría de la población (la que constituía el grueso de los partidarios de Villa) era analfabeta" (I998, t. I, 480). Este tema es sumamente importante en el análisis de la prensa revolucionaria, pues sería un error considerar al grueso de la población como los principales receptores de los mensajes periodísticos. En realidad, los periódicos -sueltos y hojas volantes- tenían como objetivo impactar en sectores medios alfabetas que se encargaban de redactar y difundir 
ideas de facciones contrarias y, paralelamente, ayudar a fortalecer la moral de sus propios dirigentes y acercarse a sectores alfabetas que no habían decidido a qué bando apoyar.

Debido a las dificultades para que los mensajes de la prensa impactaran en el grueso de la población, de bajos recursos y analfabeta, el gobierno villista utilizó otras formas de propagar sus ideales. Entre estas se encontraban ceremonias, bailes y fiestas que se organizaban cuando la División del Norte lograba importantes victorias y contaban con una gran concurrencia. Estos eventos eran "una combinación de ritual político tradicional de clase media, con música y, sobre todo, entusiasmo popular" (Katz, I998, t. I, 480).

En el verano de I9I4 la Revolución dio un vuelco sin retorno. Después de la derrota de Victoriano Huerta y el triunfo del ejército constitucionalista, en el verano de I9I4, se concretó el desmembramiento de los vencedores en el que las desavenencias entre Villa y Carranza tuvieron un lugar preponderante. El conflicto no era en absoluto nuevo, pues comenzó desde diciembre de I9I3 cuando Villa se hizo de la gubernatura del estado de Chihuahua y echó a andar una serie de reformas sociales que iban contra el proyecto político que tenía en mente el Primer Jefe (Salmerón, 2006). Así las cosas, Carranza viajó a Chihuahua en busca de recuperar un poco del poder que creía corresponderle y que Villa se había atribuido.

La complicada relación entró en crisis durante las asonadas finales contra el Ejército Federal, cuando, el Primer Jefe, en lugar de ordenar que la División del Norte ocupara Zacatecas, dirigió un telegrama a Villa y a sus hombres para que tomaran Saltillo (plaza que correspondía ocupar al ejército del noreste de Pablo González) y en su lugar, envió a Pánfilo Natera y a Domingo Arrieta a tierras zacatecanas. Finalmente, ante la dificultad de tomar la plaza, Carranza exigió refuerzos de la División, pero Villa se negó a hacerlo porque creía que eso significaba enviar a sus hombres a perder la vida. Después de un altercado entre Carranza y el jefe de la División del Norte - en el que Villa había renunciado al mando de la División 
norteña y más tarde retomó el puesto gracias a la decisión de sus hombres- el ejército villista "desobedeció" al Primer Jefe, se lanzó contra la ciudad de Zacatecas y fue recuperada el 23 de junio de I9I4.

Días después, algunos generales del Ejército del Noreste (Antonio I. Villarreal, Cesáreo Castro y Luis Caballero), le sugirieron a Villa realizar reuniones con el fin de tranquilizar la situación. El Centauro del Norte accedió y envió a tres delegados: al Ing. Manuel Bonilla, al Dr. Miguel Silva y al general José Isabel Robles. Del cuatro al ocho de julio de I9I4 se llevaron a cabo varias juntas en Torreón, que permitieron una suerte de armisticio, en el cual Villa debía reconocer la Primer Jefatura de Carranza y este, a su vez, a Villa como cabecilla de la División del Norte. En cuanto el Ejército Federal fuese derrotado se llamaría a un Convención en donde sólo las fuerzas revolucionarias estarían representadas en esa junta, con un delegado por cada mil soldados (Sánchez, 1983).

En los periódicos, específicamente en El Radical -publicación vespertina dirigida por Luis Zamora Plowes-, se trató de ocultar el inminente conflicto entre Carranza y Villa. El martes 22 de julio apareció una nota en la primera página que llevaba por título: "se confirma que han terminado las disidencias entre el jefe de la revolución y Villa." En ella se reprodujo un cablegrama que firmaba Héctor Pérez Abreu en el cual pedía mesura a la prensa en lo relativo al manejo del conflicto:

Por alto espíritu de patriotismo debe orientarse la opinión pública, puesto que el jefe de la revolución, don Venustiano Carranza, conserva dignamente la primera jefatura de la misma. El general Villa y todos los jefes que militan en el movimiento constitucionalista han hecho conocer al señor Carranza su adhesión más completa.

En todos los círculos revolucionarios se confirma que las dificultades entre los jefes del movimiento constitucionalista han terminado favorablemente para la nación (El Radical, 22 de julio, I9I4, p. I). 
En septiembre, la prensa carrancista no alentó la división entre los revolucionarios, ejemplo de esto fue una nota que apareció en $\mathrm{El}$ Liberal - diario carrancista que había sustituido al extinto periódico porfirista y huertista El Imparcial - titulada: "No existen divisiones entre el Primer Jefe del Ejército Constitucionalista y el General en Jefe de la División del Norte, Francisco Villa." En ella se aseguraba que 'ciertos espíritus perversos', con el fin de hacer una labor 'antipatriótica', afirmaban que existían importantes conflictos en los puntos de vista de Carranza y Villa. Al final agregaban: "Y nada ha sido más falso. La obra de la revolución es grandiosa, los hombres ante el impulso de la verdad, se unen y laboran por los sagrados derechos del pueblo" (El Liberal, II septiembre, I9I4, p. I).

Uno de los elementos que nos permiten comprobar los intentos por evitar que los periódicos incrementaran la escisión revolucionaria puede encontrarse en el testimonio de José Ugarte. Según él, la prensa se cuidaba muy bien de "tener oculta la verdad", sobre todo por el mandato de los principales generales que habían llegado a la Ciudad de México desde agosto de 19I4. Para Ugarte uno de los militares más ‘autoritarios' fue Lucio Blanco “[...] quien leyó siempre con profundo disgusto cuantas palabras se dijeron referentes al conflicto latente." José Ugarte continúa con su relato mostrando la fuerte influencia del general Blanco al momento en que estaba por publicarse una nota: "una mañana ordenó al señor don Gerzayn Ugarte, director de El Liberal, que se presentara sin dilación alguna en el cuartel de la calle de los Héroes [...] Llegado a la presencia del Rey, don Gerzayn se oyó amonestado como un chiquillo de escuela: 'Mucho cuidado con volver a hacer crítica de los actos del General Villa"' (Ugarte, I9I7, pp. 7-8).

Después de varios intentos para evitar una nueva guerra, que incluyó dos viajes de Obregón a Chihuahua, que han sido exaltados por la historiografía tradicional que tacha a Villa como una persona impulsiva que casi asesina a Obregón, el 24 de septiembre Villa lanzó un "Manifiesto al pueblo mexicano", en el que desconoció a Carranza (Cervantes, I960, p. 26I). Esto significó la completa ruptura entre los dos hombres. El manifiesto seguramente no estuvo dirigido al grueso 
del pueblo mexicano, "los destinatarios principales eran al parecer Zapata y los demás jefes revolucionarios que aún no se decidían por un bando" (Katz, 1998, t. I, p. 422).

Pese a ello, El Liberal continuó con su notable tendencia pro Carranza con editoriales en donde se argumentaba a favor de su labor ( $E l$ Liberal, I8 de septiembre de I9I4, p.3). Con base en el editorial se buscó legitimar la manera en que Carranza se había hecho del manejo de todos los poderes de la federación: era sin duda una respuesta a las palabras que contenía el texto villista, donde desconocieron al Primer Jefe. El 'manifiesto' villista no fue publicado por El Liberal de inmediato, el silencio es explicable, pero se rompió un mes después, ya que apareció en una primera plana, una vez que la situación militar había cambiado radicalmente y los grupos revolucionarios comenzaron a reorganizarse.

Lucio Blanco y cuarenta y nueve generales más, crearon un grupo que buscó evitar la ruptura revolucionaria: el Comité Permanente de Pacificación. El grupo contactó a los generales de la División del Norte exhortándolos a que evitaran el fracaso revolucionario; Villa y sus generales plantearon su propuesta: Carranza debía renunciar y su lugar lo ocuparía Fernando Iglesias Calderón, quien a los ojos de gran parte de los revolucionarios del Norte era un hombre neutral. Carranza rechazó nuevamente las propuestas de los generales e insistió en que sólo una junta representativa a la que él había convocado podía solucionar los conflictos existentes. El Liberal apoyó por completo el punto de vista del Primer Jefe al asegurar: "no es facultad de aquella División, ni de un Grupo Militar, resolver cuestiones de tal gravedad, sin consultar antes la voluntad nacional" (El Liberal, 29 de septiembre, I9I4, p. I).

En los últimos días del mismo mes, la Comisión Permanente de Pacificación envió a un grupo a Zacatecas para conferenciar con los villistas. El 30 de septiembre se llegó a un par de acuerdos: la suspensión total de las hostilidades y el compromiso de llevar a cabo una Convención en la ciudad de Aguascalientes, en busca de una zona neutral para conferenciar sobre el proyecto de la Revolución y 
solucionar las problemáticas del país (Amaya, I966). Tal y como lo afirmo Katz: "era una bofetada para Carranza, ya que ratificaba en gran medida los acuerdos de Torreón, que él había desconocido” (I998, t. I, p. 425).

A pesar de los intentos de la Comisión pacificadora por realizar la Convención desde un inicio en un punto neutro, Carranza llevó a cabo la Junta en la Ciudad de México. En dicho ambiente, se creó un nuevo diario que apareció el mismo día en que se inauguró la convención de la ciudad, le dieron por nombre El Pueblo que llegó para monopolizar en manos carrancistas la información. Cuando la Convención se mudó a Aguascalientes, Carranza desconoció completamente a la Junta Revolucionaria y ambos periódicos se convirtieron en los paladines del Primer Jefe. Atacaron a la Convención, que se declaró soberana a mediados de octubre, y comenzó a publicar editoriales contra los convencionistas, particularmente contra Villa. En este momento inició lo que se ha denominado como "la guerra de papel” de I9I4-I9I5 (Méndez, 20I4a).

Al iniciar noviembre, la Convención eligió al general Eulalio Gutiérrez, candidato de Obregón, como presidente provisional "por veinte días" y la ruptura revolucionaria se confirmó. Para difundir las discusiones del programa de reformas políticas, sociales $\mathrm{y}$ económicas, así como para refutar los ataques de la prensa carrancista, los convencionistas decidieron crear, el I4 de noviembre de 19I4, un órgano informativo al que pusieron por nombre La Convención. Entre sus colaboradores estuvieron Felipe Riveros, Samuel G. Ávila, el Dr. Luis Coyula, B. Mallen, Santiago González Cordero, Fernando Celada, Miguel Mendoza López Schwertfeger y, sobre todo Julián Malo Rivera; es poco lo que se sabe de estos hombres, pero gran parte de ellos se mantuvo trabajando en el diario durante todo el tiempo que se publicó.

El periódico designó como jefe de redacción a Rafael Machorro y como administrador a Federico Sor. Una de las principales características de este periódico fue que, a pesar de las dificultades sociopolíticas y militares, así como de su continuo cambio de sede, 
tuvo un solo director: Heriberto Frías (AGN, s/f, c. I26/exp. Io). La labor periodística del autor de Tomóchic, durante la guerra de facciones, ha sido poco estudiada y las líneas que dejó plasmadas en el diario oficial de la Convención revolucionaria, deben ser analizadas con mayor precisión.

De forma paralela, el periódico Vida Nueva se mantuvo atento al ambiente revolucionario. Desde septiembre de I9I4 comenzó a publicar ataques contra Carranza y a exaltar a la División del Norte como el ejército más importante que había ayudado a derrotar a Huerta (Katz, t. II, pp. 50-5I). Vida Nueva nunca circuló en la Ciudad de México, pero es importante mencionar que la ruptura periodística se dio a lo largo y ancho del país. Es decir, la construcción de relatos y correlatos no fueron un fenómeno exclusivo del centro del país, lo que reflejó también la coexistencia de muchas revoluciones construidas con la imprenta.

\section{La concordia revolucionaria. Villa "el águila del norte"}

Durante sus primeros meses de vida, La Convención trató de convencer a sus lectores de que los carrancistas sólo lanzaban calumnias y mentiras desde sus diarios (La Convención, i7 de diciembre, I9I4, p. I.) A finales de diciembre de I9I4, Frías insistió en mostrar que la "muerte de las facciones personalistas" era el fin primario de la Convención. A la par, mostró cierto favoritismo hacia la División del Norte, la ensalzaba y la elevaba como un ejemplo a seguir debido a que todos sus hombres, sobre todo Villa, habían renunciado al poder personal, en contraposición a Carranza y los suyos:

Vése cómo, no obstante la enorme fuerza moral, intelectual y militar victoriosa de los ciudadanos de la División del Norte, que traían un amor y una admiración profundísimos por su jefe el general Francisco Villa; rodeado de prestigio bélico y cívico sin precedente; vése cómo, a pesar de que las legiones 
saturadas de idolatría napoleónica son poco aptas para el raciocinio y el análisis del villismo, como facción política, dejó de existir, en el Coliseo de Morelos de Aguascalientes, el día en que la Asamblea se declaró Soberana.

En cuanto al carrancismo, ya hemos visto cómo hubo de terminar su misión política y guerrera. Surgido por un conjunto fortuito de accidentes históricos, no fue sino como un símbolo, una corte que nunca combatió, que solo recibió homenajes, una Primera Jefatura nominal y honoraria, peregrinando a la zaga de las huestes revolucionarias que iban abriéndole camino entre los escombros de las ciudades asaltadas, quienes solemnemente juraron por su honor de ciudadanos armados cumplir y hacer cumplir decisiones de la antigua Asamblea (La Convención, 30 de diciembre, I9I4, p. 3 ).

La prensa convencionista, en ocasiones, enfocó sus ataques a Carranza, pero en otras, fomentó la unión. Este conflicto permaneció durante prácticamente toda la vida del diario. La otra facción sí comenzó a incluir dentro del 'mal' a Villa y a la División del Norte, el volante redactado por Obregón contra la 'Trinidad maldita' de principios de diciembre de I9I4, dio la pauta para que Villa comenzara a ser vinculado directamente con la 'reacción' y no sólo se le reprochara su insubordinación, así como su 'negro pasado'. La prensa convencionista no mencionó en ese momento la hoja volante de los cargos concretos contra Francisco Villa, pero sí llevó a cabo una labor de desprestigio de los carrancistas, específicamente de Obregón (Méndez, 2020). Aseguraron que desde que Venustiano Carranza se había mudado con sus hombres a Veracruz, sólo se habían encargado de lanzar injurias contra la Convención, en su sección "Al margen de la Convención".

196 El periódico convencionista se dio a la tarea de relatar la forma en que los carrancistas se habían dedicado a sembrar la 'discordia' dentro de la Junta Revolucionaria. No obstante, las críticas no sólo se le realizaron a las actitudes de Carranza, sino -sobre todo- al 'traidor' Obregón, quien unos días antes había firmado la bandera mexicana y había asegurado que siempre combatiría contra el que se rebélase 
contra la Convención (La Convención, 5 de enero, I9I5, p. 2). No obstante, este ataque, que parecía abrir una brecha para futuras críticas al carrancismo y a sus hombres, fue un caso aislado y, generalmente, no dedicaron muchas líneas al desprestigio del Primer Jefe ni de Obregón en publicaciones posteriores, posiblemente porque consideraban que las fuerzas revolucionarias continuarían su proceso de reacomodo.

El cinco de diciembre de I9I4, un día después de consumarse el pacto de Xochimilco entre Francisco Villa y Emiliano Zapata para enfrentar a Carranza, apareció el primer número del periódico $E l$ Monitor. Sus talleres estaban ubicados en el casco viejo de la Ciudad de México, cerca de la Alameda, en la esquina de Colón y San Diego. El rotativo surgió de la misma maquinaria que había dado vida a $E l$ Imparcial y a El Liberal, cancelado cuando Carranza se mudó a Veracruz.

El director de El Monitor fue el periodista Luis Zamora Plowes, quien había ocupado la dirección de El Radical y años atrás el mismo cargo en el periódico villista Vida Nueva (El Radical en Ramírez, 20I0, p. I40). Zamora se mantuvo en el puesto del cinco de diciembre de I9I4 al 23 de enero de 19I5, cuando lo sustituyó Heriberto Frías. Junto a Zamora, fungieron como gerentes el futuro creador de Excélsior, Rafael Alducin y Fernando R. Galván. La información publicada divulgó la situación de la Convención, la vida citadina y las campañas militares de zapatistas y villistas. Un día después de la aparición del nuevo diario, la División del Norte y el Ejército Libertador del Sur entraron a la Ciudad de México y ocuparon Palacio Nacional (Alessio, 1979).

La consolidación de una prensa convencionista que velara por los intereses de la facción revolucionaria resulta evidente con la creación de la Oficina de Información, el II de diciembre de I9I4, por acuerdo de Eulalio Gutiérrez -entonces presidente provisional de la República - y por iniciativa del secretario de Guerra, general José Isabel Robles. Su objetivo fue la búsqueda de la unificación periodística en lo relativo a las campañas militares, con el fin de evitar la circulación de noticias falsas de los partes de guerra y de la 
situación del país en general. En la oficina se procuró desmentir los falsos rumores y devolver la calma a los lectores que vivía en exaltación continua debido a la desinformación imperante.

La ocupación de la metrópoli por los convencionistas duró poco tiempo. A mediados de enero de 1915, Eulalio Gutiérrez decidió romper la alianza con los norteños y sureños, partió de la capital y dejó vacante la presidencia provisional. Roque González Garza, presidente de la Convención, fue nombrado Encargado del Poder Ejecutivo. A escasos diez días de ocupar el puesto, él y la Convención se trasladaron a Cuernavaca, Morelos, para continuar sesionando. Es importante destacar que la prensa convencionista nunca estuvo en manos del grupo de Gutiérrez, sino en manos de zapatistas y algunos villistas.

A finales de enero de 1915, antes de abandonar la Ciudad de México, debido al arribo de los hombres de Obregón, La Convención puso énfasis en la unión de sus filas y la desaparición de las ambiciones personales. La Revolución dividida en cuatro grandes zonas: Norte (Villa), Noroeste (Maytorena), Sur (Zapata) y en el Centro, probablemente Eulalio, eran una sola. Los nombres eran parte del pasado:

Quien dice Villa, [...] da a entender, no el hombre más o menos valiente y apto para resolver por el tino y la audacia, con una batalla, toda una campaña, o con una palabra, todo un problema social; no, que esos méritos, por grandes que sean son personales, y mueren con la persona, o se hacen negativos por las enfermedades del alma y del cuerpo, que contraer suelen todos los que se encumbran en las vertiginosas cimas del poder... no; quien dice Villa, hoy, significa, la victoriosa rebelión de la gente campesina chihuahuense contra las satrapías feudales de los Terrazas; el triunfante anhelo de justicia y equidad y la consolidación del derecho del labriego fronterizo, derecho convertido por el heroísmo, en realidad: todo el norte restituido a la equidad por la razón y la fuerza (Frías, I9I5, p. 2). 
Frías y La Convención continuaron su labor de desprestigio contra el movimiento carrancista. En una nota editorial del 22 de enero de 1915 el queretano desarrolló una comparación entre Pascual Orozco y Venustiano Carranza, como antes lo había hecho El Liberal con Villa. Orozco, héroe de la Revolución maderista fue "infectado por los científicos" que combinaron "el disolvente veneno de la adulación, con el embriagador tóxico del dinero", que lo llevó a levantarse contra Francisco I. Madero, "un civil como Juárez, físicamente débil, pero intocable y fuerte como la Justicia." Por ende, Carranza parecía estaba cayendo en el mismo error que Orozco, que sólo combatió por "rapiñas y personas", contrario a Villa y a Zapata (La Convención, 22 de enero, I9I5, p. 2).

Obregón y sus hombres ocuparon la Ciudad de México a finales de enero, pero, una vez más, la desocuparon a las pocas semanas: era un lugar difícil de mantener y sin un claro papel estratégico. El sonorense había conseguido difundir los ideales carrancistas en la ciudad y ganar el apoyo de un sector obrero organizado, representado por la Casa del Obrero Mundial. Debido a los sueltos que circularon, leyenda negra de Villa y del villismo cobró gran fuerza durante la toma de la Ciudad de México por parte de Obregón (Méndez, 20I4b).

La Convención se trasladó a Cuernavaca y, mientras permaneció en dicho sitio, la propaganda provillista nunca se detuvo, pese a estar en territorio netamente zapatista, en donde se dividieron paulatinamente los delegados del norte y sur. Villa, como el brazo armado del movimiento convencionista, siempre fue exaltado y confrontado con la personalidad del Primer Jefe. Entre el I4 y el I7 de febrero La Convención publicó una columna intitulada "Hechos y razones contra las calumnias de A. Obregón” la refutación de algunos de los cargos concretos que Obregón había lanzado a Villa en su hoja volante "La trinidad maldita", sus autores fueron Francisco Lagos Cházaro y el teniente coronel Juan Antonio Acosta. Punto por punto el manifiesto obregonista fue "desmentido" por el futuro encargado del poder ejecutivo de la Convención (La Convención, I6 de febrero, I9I5, p. 2). 
Asimismo, en La Convención se aseguró que aquéllas personas que llegaban a Cuernavaca, provenientes de la Ciudad de México, referían el odio popular de todas las clases sociales hacia Carranza y toda la 'facción del bandidaje.' Para comprobar la animadversión citadina hacia el carrancismo, el periódico convencionista difundió que en hojas escritas a mano o en máquina se invitaba a todos los ciudadanos a sacudirse del yugo del 'siniestro' Obregón, aclamando a Villa, a Zapata, a la Convención como los 'verdaderos' luchadores de la Revolución. Ademas, agregaban que en las mañanas aparecían, fijados en las paredes, carteles sugestivos contra el carrancismo ( $\mathrm{La}$ Convención, 27 de febrero, I9I5, p. 2).

Villa y el villismo, dentro de la Convención, siempre fueron vistos como uno de los tantos miembros de esa gran 'unión revolucionaria' que significó esta facción, no obstante -y pese a luchar contra el personalismo "tóxico", como lo llamo Frías - la apología villista fue más notoria conforme avanzaron los días en Cuernavaca. Se comenzaron a publicar una serie de documentos que mostrara la otra cara de la historia, muy distinta a la que la prensa carrancista defendía (que incluso hasta nuestros días, ha permeado la interpretación de los hechos acaecidos en aquellos meses, muy vinculado con una suerte de 'leyenda negra' de Villa). Entre febrero y marzo de I9I5, en la prensa convencionista se publicó una sección llamada "Documentos históricos de la Revolución" para refutar la idea de que Villa había traicionado a Carranza y de era el culpable de la lucha que se estaba desarrollando (La Convención, I9 de febrero y 2I de marzo de i9I5).

De forma paralela, la prensa convencionista exaltó a sus principales líderes. El siete y el nueve de marzo, La Convención publicó un par de artículos en donde enaltecía a Zapata y a Villa, su autor fue Samuel G. Ávila y llevaron por título "Las Dos Águilas de la Convención: Villa y Zapata”. La primera entrega estuvo dedicada a Zapata, no obstante, el autor explicaba la situación del movimiento del Primer Jefe: “el carrancismo, en último análisis, es un moribundo que sólo espera la necesaria operación del cirujano para ser cadáver y llegar a la nada. Esperad; los agudos clarines del Norte y el redoble marcial de los 
tambores del Sur; ejecutarán a tiempo una marcha fúnebre en recuerdo del vencedor" (La Convención, 7 de marzo, I9I5, p. 4)

El nueve de febrero 'el águila del norte', Pancho Villa, fue descrito como el sucesor de Madero, a quien siempre defendió debido a su fuerte apego por los regímenes democráticos; el autor pidió que se dejara de lado el pasado de Villa, pues "él había resucitado" cuando formó la División del Norte. Villa era descrito como el 'gran hombre de mármol' que no se derrumbaba ante ninguna situación, por más difícil que ésta fuera: "El General Villa, lo diremos en síntesis, es de la misma naturaleza de los hombres de Plutarco, aman a su Patria y lucha por esa misma Patria con la entereza de los que ven, dibujarse en el porvenir, la realidad de una plan que es la salvación de los principios y no de las personas, que es el defecto capital del carrancismo" (La Convención, 9 de marzo de I9I5, p. 3).

A la par, la columna aseguraba que Villa y sólo Villa, "el brazo armado de la Revolución”, tenía un programa de reformas sociales y a quien se debía el triunfo frente a los 'aristocráticos' huertistas. Villa era el cerebro de la lucha armada:

Las principales plazas tomadas a sangre y fuego, que han originado muchas envidias, justifican, de modo evidente, a la vez que el valor temerario, las aptitudes que caracterizan al jefe de las operaciones del Norte, que cual un Napoleón ha arrollado al enemigo como Huerta y al otro enemiguillo como Carranza, que ha dividido a los compañeros en tendencias o en ideales, teniéndolo a raya; sin dejarlo alear más allá de Orizaba, del Estado de Veracruz (La Convención, 9 de marzo de I9I5, p. 4).

El carrancismo se "moría de fatiga" ante la grandeza del 'águila del Norte' -en conjunción con el 'águila del Sur'- de Villa sería la victoria. Pese a ello, en el seno de la Junta Revolucionaria se mantuvieron las divergencias en torno a los enemigos de la Revolución. El I5 de febrero la Comisión de Guerra presentó un dictamen en el que se estableció que "los miembros de la Convención que no se 
incorporaran a las órdenes de ésta serían considerados como desertores, dados de baja, juzgados militarmente en caso de pertenecer al ejército o, si eran civiles, perderían sus derechos para ocupar cargos públicos por cinco años; los jefes militares y oficiales serían dados de baja por traidores y juzgados conforme a las leyes militares en casa de ser capturados" (Fabela, I97I, p. 303). Lo que provocó un intenso debate; los delegados del sur, principalmente Otilio Montaño y Rafael Pérez Taylor, aceptaron y defendieron el dictamen, mientas los norteños vieron excesivo el castigo para los civiles. Es importante resaltar la postura de los delegados Marines Valero y Ángel Castellanos, quienes asentaron que no podía acusarse de contrarrevolucionarios ni traidores a los carrancistas, pues estos también eran revolucionarios y sólo diferían en su tendencia y acciones.

En este punto, puede notarse lo que asegura Felipe Ávila con respecto a las distintas actitudes que se tomaron en torno a la cuestión del enemigo de la Revolución; los zapatistas eran más intransigentes, mientras los villistas mostraron mayor flexibilidad y moderación, probablemente con el objeto de lograr nuevas alianzas en el futuro. En el fondo, el problema era la falta de consenso al momento de "crear" al enemigo común y al que había que derrotar: los carrancistas siempre se mostraron intransigentes en su prensa, los convencionistas no lo hicieron así, por el contrario siempre vio en Villa al brazo armado de su movimiento, no obstante, el grado en que entendieron a Carranza como su némesis fue distinto entre las facciones que componían a la Junta Revolucionaria.

La pluma de Frías no descansó en Cuernavaca, contrario a ello, realizó lo que fue -posiblemente- uno de los ataques más directos al Plan de Guadalupe y a sus adiciones del I2 de diciembre de I9I4. Frías en un nota editorial intitulada "Apocalipsis revolucionario" pintó a un Carranza que, empujado por "el Satanás del personalismo tóxico y venal" se obstinó en imitar a "Díaz y a Huerta disfrazándose de convencionista, plagiando a la Convención, él, el primer personalista, su programa de principios, proclamando él, el Primer Terrateniente, la nacionalización de la tierra" (La Convención, I8 de febrero, I9I5, p. 
2). La idea de que Carranza había 'copiado' las ideas villistas y zapatistas posiblemente encuentra aquí su génesis, pues según el autor de Tomóchic el 'eterno' enemigo de Villa y Zapata buscó con las adiciones al Plan de Guadalupe "vestirse con la blusa suriana" y calzarse con "las botas chihuahuenses, ciñendo el machete libertador de Emiliano Zapata y terciando la purificadora carabina de Francisco Villa."

El manifiesto del I2 de diciembre era para el director de la prensa convencionista "vergonzoso y tristísimo" pues plagiaba las ideas de repartos de tierras y de fraternidad nacional por las que tanto había velado la Junta Revolucionaria. La crítica, una vez más, se dirigió al personalismo y el poco diálogo en torno a las reformas sociales, por ello el manifiesto sólo mostraba uno de los monstruos que anunciaba la futura llegada del apocalipsis, en tono satírico:

Pero eso sí, no obstante el disfraz, a pesar del plagio y sobre la propia careta y contra el engaño mismo, copiado de Porfirio y Victoriano, él, Carranza, no renuncia a ser Carranza, el Primer Jefe, el único, el Absoluto, el sumo Dictador, el de hoy, el de mañana, el Plan de Guadalupe que sólo dice que él, como dios, ha sido, es y será Primer Jefe de la Nación mexicana.

En efecto, en ese Manifiesto, las promesas de leyes color de rosa de reparto de tierras, de justicia, etc., etc., no son sino la cola del monstruo, porque lo esencial - lo capital- la cabeza y todo el monstruo no es sino cabeza y cola- estriba en que ante todo, sobre todo, después de todo, y contra todo, como en el evangelio de San Juan, está el plan de Guadalupe" ( $\mathrm{La}$ Convención, I8 de febrero, I9I5, p. 2).

Al mismo tiempo, el tres de marzo de 1915, la Convención comenzó el estudio del programa de reformas políticas, económicas y sociales, que pese a que los ideales ya se habían planteado desde que la propia Junta se definió como soberana en Aguascalientes, era "urgentísima" su discusión (La Convención, 5 de marzo, 1915, p. 2). 
El Io de marzo de I9I5, Obregón abandonó la Ciudad de México y los convencionistas dejaron Cuernavaca para regresar a su antigua sede. Al día siguiente, La Convención publicó uno de los pocos "Extras" con los que contó en su corta historia. En él narró la toma de la Ciudad de México por parte de los hombres de Villa y Zapata (La Convención, II de marzo de I9I5, p. I). Tras la recuperación de la metrópoli, el I2 de marzo de 1915, se imprimió por última vez La Convención en Cuernavaca. El 24 de marzo el periódico volvió a aparecer tras el retorno de la asamblea a la Ciudad de México:

La unión de Norte y Sur es un hecho innegable, la fortaleza de tal unión se está palpando en los frecuentes triunfos que se obtienen sobre las facciones personalistas.

Reanudamos hoy nuestra labor, que había quedado suspensa en Cuernavaca hace diez días.

Revolucionarios de Norte y Sur, adelante. La justicia está con nosotros y presentimos cercana la hora máxima del triunfo.

A los revolucionarios descarriados, sólo pedimos una cosa: que nos escuchen; y si logramos taladrar con una raya de luz su ofuscamiento...entonces que decida su hombría de bien ( $\mathrm{La}$ Convención, 24 de marzo de I9I5, p. I).

Al mismo tiempo, el mayor del Ejército convencionista, Juan de Dios Avellaneda, llamó a la unión de los revolucionarios en aquel momento. La unificación en torno a la Junta Revolucionaria sería el único camino para que se realizaran los ideales revolucionarios en busca de transitar a la "democracia y a la verdadera ciudadanía" ( $L a$ Convención, 24 de marzo, 19I5, p. 2).

Una semana después de desalojada la Ciudad de México por las 204 tropas de Obregón, el 2I de marzo de 1915, reapareció El Monitor, que había dejado de publicarse ante la ocupación de las tropas carrancistas. Frías, en el editorial de la misma fecha, lamentó el comportamiento de los carrancistas en la ciudad, que habían dejado en pésimas condiciones las instalaciones del diario convencionista ( $E l$ Monitor, 27 de marzo de I9I5, p. 2). Para la reanudación de las labores del periódico echaron mano de útiles y maquinarias tomados de otras 
oficinas adictas a su movimiento, sin embargo, la segunda época de El Monitor tuvo notables defectos debido a la estrategia carrancista de hacerse de sus maquinarias. La disminución de sus páginas fue continua: en enero tenía 8 , en marzo 6 y en mayo 4 . Su precio siempre fue de 5 centavos.

A los pocos días, el miércoles 24 de marzo de I9I5, se anexó en el periódico de La Convención una nota del Dr. Luis Coyula, titulada "El Plan de Ayala" en la cual veía la bandera de la revolución, que habría de permitir el tratamiento de las 'enfermedades' del país" ( $\mathrm{La}$ Convención, 24 de marzo de I9I5, p. 2). Las discusiones en torno a la cuestión agraria fueron menos acaloradas en la Convención que lo relativo a la reforma obrera. El villismo, desde finales de I9I3-cuando tomó el estado de Chihuahua- se había dedicado a legislar en torno a la reforma agraria. A lo largo de I9I4 una de las principales metas de Villa y sus hombres, fue la restitución de tierras a las personas que habían sido despojadas de ellas, destruir el latifundismo e impulsar la pequeña propiedad.

Meses después, el 24 de mayo de I9I5, ya en plena guerra contra Obregón en León, Villa publicó su propia ley agraria con la cual buscaba atender las características y necesidades específicas de cada estado, realizando diferencias en cuanto a la cantidad de hectáreas que se podía poseer según el clima y la calidad de la tierra. Impulsó la creación de la pequeña propiedad y la formación de empresas agrícolas, en este caso el reparto estaría supervisado por el municipio, caso contrario a la ley agraria carrancista, según la cual el gobierno federal vigilaría directamente el reparto. No obstante, según la ley villista, sí debía existir una indemnización a los propietarios de las tierras y se permitirían donaciones sólo para los pueblos indígenas (Córdova, 1980). 


\section{La ruptura convencionista y el fin de la prensa villista}

La ocupación de las instalaciones de los periódicos convencionistas y el robo de parte de la maquinaria por parte de los carrancistas fue un golpe certero contra las labores propagandistas de la Convención en su lucha por dar a conocer sus ideales. Además, el regreso de los convencionistas a la Ciudad de México, sumida en una crisis sociopolítica y económica muy fuerte, sacó a relucir las diferencias entre los delegados del norte y de sur.

A finales de marzo de I9I5, en el seno de la Convención, el gabinete de Roque González Garza, nuevamente en la capital, quedó definido después de dos meses. Lo componían cuatro villistas y cinco zapatistas. De los villistas, solamente Lagos Cházaro, secretario de Gobernación, se encontraba en la Convención, ya que los otros tres ocupaban los mismos puestos en Chihuahua, en el gobierno de Villa, desde dos meses atrás (Ávila, I99I).

Después de las dos derrotas villistas en Celaya, en abril de I9I5, los conflictos entre los delegados del norte y del sur aumentaron. Destacó la mala relación entre Manuel Palafox y el encargado del Ejecutivo, así como la precariedad de recursos del gobierno de la Convención. Además, cada día era más evidente que villistas y zapatistas tenía objetivos distintos (Ávila, I99I). El fondo real de dicho conflicto era la búsqueda de la hegemonía dentro de la Convención. A finales del mismo mes, González Garza destituyó a Palafox y la Convención ratificó la decisión el 29 de abril de I9I5. Zapata criticó el movimiento y exigió que se reinstalara al exencargado de agricultura, sin lograr los resultados esperados. Aún alejado del puesto, Palafox continuó con sus labores y su relación con el encargado del Ejecutivo se complicó más hasta hacerse insostenible.

El i8 de mayo de 1915, Rafael Pérez Taylor sustituyó a Frías en la dirección de uno de los más importantes órganos informativos de la Convención: El Monitor (Ramírez, 20Io). El suceso reviste una enorme importancia ya que significó el fin de la concordia revolucionaria de la Convención en la prensa. El periódico convencionista, ahora bajo 
el mando de Pérez Taylor, no continúo la labor unificadora dentro de la Junta Revolucionaria, que había impulsado Frías desde su designación como director en enero del mismo año. Su tendencia mutó para ser notablemente zapatista. El día que tomó la dirección del rotativo, Pérez Taylor publicó una nota con el nombre de "Nueva ruta", en la cual aseguró que no llevaría a cabo "politiquería de partido", sino que se enfocaría en impulsar la propaganda de los ideales revolucionarios. La nota no fue del agrado de Heriberto Frías, quien le había cedido el cargo después de tener una charla con González Garza para elegir su sustituto y por problemas oftalmológicos que debía tratarse. Este cambio en la dirección de uno de los diarios convencionistas reflejó el inicio de la ruptura de la prensa convencionistas y el alejamiento de las posturas villistas y zapatistas.

Frías insistió que todo lo que se había publicado en el diario convencionista tuvo por objetivo, en primer lugar, atacar a los enemigos de la Revolución (militarismo, clero, cientificismo, sectores medios y la banca); y, en segundo lugar, impulsar una "labor de propaganda unionista, tenaz a favor de la Convención, y de la Unión Norte-Sur" (El Norte, I9 de mayo, I9I5, p. I). Mientras Frías permaneció como director de La Convención y El Monitor, los periódicos convencionistas mostraron cierta homogeneidad. Con el cambio en la dirección, la línea editorial de El Monitor sufrió transformaciones que reflejaron el momento dentro de la Convención y mermaron su capacidad para consolidar su propaganda y unificar su criterio (Méndez, 20I5).

El siete de junio, la Asamblea trató informalmente algunos problemas de distinta índole, entre los que se encontraba la clausura de los periódicos El Monitor, El Norte y El Radical, cerrados poco antes por órdenes directas de Zapata, debido a que eran enemigos del Plan de Ayala (La Convención, 7 y 8 de junio de I9I5, p. I; The Mexican Herald, 8 de junio de I9I5, p. I). Pérez Taylor, director del primero, pidió explicaciones sobre el cese de la publicación; los zapatistas por su parte, aplaudieron la conducta del general Santiago Orozco, quien había clausurado los diarios con una cincuentena de hombres. La 
imprenta, en donde se editaba el primero de los diarios, fue tomada por el general Orozco y quedó a disposición del Ejército del Sur para comenzar la publicación de un nuevo órgano informativo

El siete de junio de I9I5, en medio de esa agitación periodística, renunció el encargado del Poder Ejecutivo, Roque González Garza. Habían sido tres meses de intensas discusiones en el seno de la Convención. Un día después, Francisco Lagos Cházaro - quien había sido secretario de Gobernación de González Garza - fue elegido para ocupar el cargo (Ávila, I99I; Quirk, 1962). El io de junio, Lagos Cházaro tomó posesión del cargo y volvió a nombrar a Palafox como Secretario de Agricultura; el resto de su gabinete quedó conformado por cinco villistas y tres zapatistas, aunque en realidad estos últimos tenían mayor peso (Amaya, I966). Terminaba así una etapa en donde había existido cierto equilibrio entre los representantes del Ejército Libertador del Sur y la División del Norte. La situación de la Soberana Convención Revolucionaria era precaria, en el Bajío Villa había perdido una nueva batalla en la estación ferroviaria de Trinidad (Méndez, 20I5).

La prensa convencionistas continuó su desmoronamiento. El i5 de junio, pese haber aparecido el primer número de un nuevo diario de tendencias más vinculadas con el zapatismo, El Combate, afirmó que la Oficina de Información sería clausurada en pocos días debido a los bajos fondos con los que contaba la Junta Revolucionaria. Esta dependencia no había dejado de funcionar desde su creación, en diciembre de 19I4, incluso cuando la Convención regresó de Cuernavaca, el I3 de marzo, y por órdenes del Comandante Militar, general Amador Salazar, la oficina fue reinstalada; Roque González apoyó la decisión y dos días después ya funcionaba de nuevo. Sin embargo, por acuerdo del general Robles, oficial mayor de la Secretaría de Guerra y Marina, la oficina que recientemente había quedado a cargo de dicha secretaría debía ser clausurada "en vista de que actualmente no son muchas las publicaciones a las que hay que proporcionar noticias $y$, sobre todo, se desean hacer algunas economías" (El Combate, I6 de junio, I9I5, p. I). 
En ese contexto aparecieron periódicos que reflejaron la ruptura periodística: El Combate, EL Renovador y El Norte. El primero tuvo un precio de cinco centavos y su director fue Felipe Santibáñez, mientras Felipe Gómez tomó el cargo de gerente. Este diario ocupó los talleres en donde se publicaba El Monitor e inmediatamente comenzó a realizar una intensa labor pro-zapatista, Villa apareció en las líneas del periódico como aquél que habría de llegar a encontrarse con el "águila del sur" para salvar a la población de la ciudad de las huestes carrancistas. No obstante, todo lo relacionado con los sureños fue subrayado.

El Renovador. Diario de la mañana, apareció por primera vez el miércoles I6 de junio de I9I5 y mostró el inicio del fin de la existencia de prensa villista en la Ciudad de México. La redacción firmó una nota intitulada "Nuestro Programa" en la que definió las dos principales metas del periódico y criticó a los antiguos diarios que se habían publicado en sus talleres, entre los que se encontraban $E l$ Imparcial, El Liberal y el periódico convencionista El Monitor. Villa y sus hombres no fueron mencionados como pilares revolucionarios. Luis Méndez, el director de El Renovador, era un ideólogo del zapatismo que en las sesiones de la Convención se había mostrado la mayoría de las veces contra las propuestas de los delegados norteños (El Renovador, I6 de junio, I9I5, p. 3).

El Renovador tuvo corta vida, pues su número final apareció el 3I de julio de I9I5; no obstante, del Io al 2I de julio no fue publicado y sólo alcanzó los 37 ejemplares, incluso el 23 de julio Luis Méndez dejó de ser su director y ocupó su lugar Enrique Bonilla, acompañado de Carlos M. Ortega como jefe de redacción. El Combate vivió un proceso similar pues se inauguró el 17 de junio y desapareció el 29 de julio. Ambos periódicos fueron los representantes de la última época de la prensa que veló por la Convención, en los postreros meses con tendencias mucho más zapatistas.

Otro periódico que mostró la descomposición periodística de la Convención fue El Norte. Este rotativo se publicó por primera vez el 2I de abril de I9I5 en el edificio "La Palma" del Callejón de Bilbao, 
después de la segunda batalla en Celaya. Su jefe de redacción fue Armando Vargas y José González M., como su secretario. La primera plana del mismo día relató la lucha que se efectuaba en el Bajío; las noticias fueron deformadas y se aseguró que los hombres que seguían a Obregón lo habían abandonado (El Norte, 2I de abril, I9I5, p. I). Para El Norte, la batalla en Celaya se extendió hasta mayo, cuando el ocho Villa había conseguido "limpiar de carrancistas" las vías férreas. En la primera plana del I8 de mayo de I9I5 se afirmó: "Se ha desarrollado una gran batalla entre León y Silao. Después de cinco días de una incesante lucha las fuerzas de la Div. del Norte infligieron tremenda derrota a los carrancistas" (El Norte, i8 de mayo, I9I5, p. I). La peculiaridad de este rotativo fue que mostró con precisión la "reconstrucción de la campaña militar victoriosa" de Villa, quien, supuestamente, había triunfado en el Bajío.

Por falta de papel, El Norte dejó de publicarse del seis de junio al cuatro de julio. A su regreso, el periódico celebró un "triunfo" de Villa en Lagos de Moreno (El Norte, 8 de julio de I9I5, p. I; también $\mathrm{El}$ Combate, 9 de julio de I9I5, p. I). El ocho de julio del mismo año apareció por primera vez Rafael Pérez Taylor como director, quien modificó la línea editorial del periódico: de un acendrado villismo pasó a exaltar a los sureños. Sin embargo, el periódico afirmó que Villa pronto estaría en la Ciudad de México para encontrarse, por segunda ocasión, con Zapata. Fue el último número de este periódico.

Paralelamente, a finales de junio de I9I5, con las tropas del general Pablo González en las goteras de la Ciudad de México, la Convención vivió sus últimos momentos en la misma. Una de sus acciones conclusivas fue proponer un armisticio y adoptar como el programa de la Revolución un híbrido de las adiciones del Plan de Guadalupe, 210 Convención, que continuaba discutiéndose (Ávila, I99I, p. 2II), lo que fue completamente rechazado por González.

El nueve de julio, La Convención, diario oficial de la Junta Revolucionaria, dejó de publicarse. Un día después varios de sus delegados se dirigieron a Toluca, en donde permanecieron algunas 
semanas. El 24 de julio de I9I5, algunas herramientas para continuar publicando el periódico fueron trasladadas a la ciudad mexiquense (AGN, s/f, 6o/exp. 25/2). La crisis económica-militar-política que enfrentó el convencionismo imposibilitó su reaparición.

El dos de agosto de I9I5 los carrancistas ocuparon la Ciudad de México definitivamente, ningún diario contrario al carrancismo sobrevivió. En pocas palabras, la oposición impresa, en el contexto de la lucha de facciones, encontró aquí su fin. Junto a las dificultades económicas, políticas y militares, también es importante subrayar que con la recuperación de la capital del país por parte de los carrancistas, la fábrica de papel de San Rafael, que estaba en manos de los zapatistas desde el I2 de agosto de I9I4 (Espejel, 2000), no pudo satisfacer las necesidades de la Junta Revolucionaria, que se encontraba ahora en Toluca, ya que transportar el material era por demás complicado debido a la ocupación de la metrópoli por parte de las huestes de Carranza.

La historia de la Convención y, específicamente de los villistas en ella, fue corta desde que abandonaron la Ciudad de México, el in de julio de 19I5. La Junta se trasladó a Toluca, debido a que el general Francisco Coss tomó Churubusco e impidió el paso hacia tierras morelenses (Amaya, 1966). Los delegados que llegaron a la capital del Estado de México disminuyeron, sólo quedaban 65 y la mayor parte eran zapatistas "varios de los delegados norteños se separaron definitivamente de ella al marcharse hacia el encuentro con los restos del villismo" (Ávila, I99I, p. 2I2). Lagos Cházaro ordenó la formación de un cuerpo armado para proteger a su gobierno, la Brigada Convención, que estuvo a las órdenes del general Federico Cervantes y del coronel Portillo; la situación provocó que aumentase el descontento de los miembros sureños, como el general Genovevo de la $\mathrm{O}$, quien desarmó sorpresivamente a los hombres de Portillo.

Lagos Cházaro escribió dos cartas a Villa para informarle la situación; puso énfasis en las dificultades surgidas entre norte y sur: "La intransigencia y la mala fe de los malos elementos del Sur han abierto un abismo entre ellos y nosotros. Sus tendencias en nada se parecen 
a las nuestras, ellos representan la mezquina ambición del fracasado que delira con las grandezas. [...] Desleales por naturaleza, desconfían y se preparan para ser nuestros enemigos" (Amaya, I966, pp. 433-435). Lago Cházaro aseguró que el villismo tenía un par de enemigos: "el militarismo de Carranza y el anarquismo absorbente de Morelos" que había sido defendido a ultranza por dos periódicos, seguramente El Combate y El Renovador. El único camino que creía podría salvar a los villistas era al lado de su líder, Francisco Villa (Fabela, I97I, p. 22I).

Durante la segunda mitad de julio y gran parte de agosto, el "Proyecto de Reformas Económicas, Políticas y Sociales” no fue discutido, sólo hasta el 26 de agosto se completó el quórum. Un mes después, el 27 de septiembre de I9I5, quedó totalmente aceptado y listo para su publicación, pero la guerra estaba perdida. Tan sólo dos semanas después de aprobarse el "Proyecto revolucionario" de los convencionistas, los villistas se separaron del bando del sur y emprendieron su camino hacia el norte, custodiados por el general Benjamín Argumedo y Federico Cervantes. Después de la debacle, muchos delegados villistas se exiliaron en otros países, como los exencargados del Ejecutivo, Roque González Garza, en Estados Unidos (Ávila, I99I) y Francisco Lagos Cházaro, quien se refugió en Centroamérica, primero en Costa Rica, luego en Honduras y, finalmente en Nicaragua. El ejército villista, después de una fallida campaña en Sonora, se desintegró a finales de I9I5; el Centauro del Norte regresó a sus orígenes: la guerra de guerrillas.

\section{Conclusiones}

La prensa villista debe entenderse mucho más allá de Vida Nueva y del Periódico Oficial de Chihuahua que se publicaron en la zona villista. La lucha de facciones y la reorganización de las fuerzas revolucionarias generaron una reconfiguración de la prensa a nivel nacional y especialmente en la Ciudad de México. 
Entre I9I4 y I9I5 se desarrolló una "guerra de papel” de la que salieron airosos los carrancistas, pero ello no significa la inexistencia de una contraparte organizada que logró consolidar algunos mensajes propagandísticos que fueron divulgados con gran asiduidad en estos meses. La prensa convencionista logró crear un departamento específico para el manejo y control de la información, dato que la historiografía no suele destacar. Fueron cinco los principales diarios convencionistas que se crearon al calor de la guerra: La Convención, El Monitor, El Renovador, El Combate y El Norte.

No obstante, la difusión de opiniones favorables al villismo tuvo en los meses de diciembre de I9I4 a abril de I9I5 su mejor etapa, pues de mayo a julio del último año zapatistas y villistas se escindieron y la prensa quedó prácticamente en manos del grupo liderado por el caudillo del sur.

Lo hasta aquí relatado permite comprender la manera en que, a la par que se llevaban a cabo enfrentamientos militares que decidieron buena parte del futuro del país, también se construyó todo un engranaje propagandístico para legitimar a los hombres y a sus respectivos movimientos. La leyenda negra del villismo, difundida en la prensa carrancista y que ha permeado parte de la historiografía, encontró su contraparte en las publicaciones que hemos analizado en este artículo. Esto nos lleva a destacar la forma en que se construyen y reconstruyen los hechos históricos: la propaganda puede convertirse en la versión predominante de un acontecimiento. De ahí la importancia de estudiar y comprender a la prensa villista en sus distintas etapas durante la lucha de facciones.

Referencias

AGN [Archivo General de la Nación]. (s/f). Fondo Gobernación/Periodo Revolucionario [c. I26/exp. Io]. Ciudad de México. 
AGN. (s/f). Fondo Gobernación/Periodo Revolucionario [c. 6o/exp. 25/2]. Ciudad de México.

Alessio Robles, V. (I979). La Convención Revolucionaria de Aguascalientes. México: Instituto Nacional de Estudios Históricos de la Revolución Mexicana.

Alonso, P. (2015). La historia política y la historia de la prensa: los desafíos de un enlace. En A. Pineda Soto (coord.), Recorrido de la prensa moderna a la prensa actual (pp. II-34). Morelia: Universidad Michoacana de San Nicolás de Hidalgo / Red de Historiadores de la Prensa y el Periodismo en Iberoamérica / Universidad Autónoma de Querétaro.

Amaya, L. (1966). La Soberana Convención Revolucionaria, I9I4-I9I6. México: Trillas.

Anderson, M. (2000). Pancho Villa's Revolution by headlines. Oklahoma: University of Oklahoma Press

Ávila, F. (199I). El pensamiento económico, político y social de la Convención de Aguascalientes. México: Instituto Nacional de Estudios Históricos de la Revolución Mexicana / Instituto Cultural de Aguascalientes.

Cervantes, F. (1960). Francisco Villa y la Revolución. México: Alonso.

Córdova, A. (1980). la ideología de la revolución mexicana. La formación del nuevo régimen. México: Era.

Cosío Villegas, D. (1972). Historia Moderna de México (tomo X). México: Hermes.

El Combate. (I9I5, 9 de julio).

El Combate. (I9I5, i6 de junio).

214 El Liberal. (I9I4, II de septiembre).

El Liberal. (I9I4, I8 de septiembre).

El Liberal. (I9I4, 29 de septiembre).

El Monitor. (1915, 27 de marzo).

El Norte. (I9I5, 2I de abril). 
El Norte. (1915, I8 de mayo).

El Norte. (1915, I9 de mayo).

El Norte. (I9I5, 8 de julio).

El Radical. (I9I4, 22 de julio).

El Renovador. (I915, I6 de junio).

Espejel, L. (2000). El costo de la guerra. La Compañía Papelera San Rafael y el financiamiento zapatista. En Estudios sobre el zapatismo (pp. 269-29I). México: Instituto Nacional de Antropología e Historia.

Fabela, J., y Fabela, I. (I97I). Documentos históricos de la Revolución mexicana. México: Jus.

Frías, H. (I9I5, I2 de enero). La Convención.

Garciadiego, J. (1995). La prensa durante la Revolución Mexicana. En A. Cano Andaluz (coord.), Las publicaciones periódicas y la Historia de México (pp. 7I-88). México: Universidad Nacional Autónoma de México.

Katz, F. (2000). Pancho Villa (t. 2). México: Era.

La Convención. (I9I5, 5 de enero).

La Convención. (I9I5, 22 de enero).

La Convención. (1915, I6 de febrero).

La Convención. (I9I5, I8 de febrero).

La Convención. (I915, I9 de febrero).

La Convención. (1915, 27 de febrero).

La Convención. (I9I5, 5 de marzo).

La Convención. (I9I5, 7 de marzo).

La Convención. (I9I5, II de marzo).

La Convención. (I9I5, 2I de marzo).

La Convención. (I9I5, 24 de marzo). 
La Convención. (I9I5, 7 de junio).

La Convención. (I9I5, 8 de junio).

La Convención. (I9I4, I7 de diciembre).

La Convención. (I9I4, 30 de diciembre).

Matute, A. (1995). Prensa, sociedad y política (I9II-I9I6). En A. Cano Andaluz (coord.), Las publicaciones periódicas y la Historia de México (pp. 64-70). México: Universidad Nacional Autónoma de México.

Méndez, F. (20I4a). ¿Una querella silenciosa? La guerra de papel en los inicio de la lucha de facciones: el caso carrancista (agostodiciembre de 19I4). Letras Históricas, (IO), II5-I48.

Méndez, F. (20I4b). ¡Vámonos para Veracruz! La prensa carrancista y su proyecto revolucionario. Del puerto a la Ciudad de México (noviembre I9I4-marzo I9I5). Ulúa. Revista de historia, sociedad y cultura, (24), I45-I76.

Méndez, F. (20I5). La prensa de la Convención revolucionaria en la Ciudad de México. La ruptura periodística entre villistas y zapatistas. Diálogos de la comunicación. Revista académica de la Federación Latinoamericana de Facultades de Comunicación Social, (90), I-I8.

Méndez, F. (2020). Francisco Villa en la prensa carrancista. La construcción del adversario (I9I4-I9I5). Bibliographica, 3(I), 2II240 .

Quirk, R. (1962). La Revolución Mexicana, I9I4-I9I5. México: Azteca.

Quirvan, G. (20I9).El periódico El Pueblo y la propaganda política carrancista (octubre de I9I4-enero de I9I5). Bibliographica, 2(2), 216 I3I-I70.

Ramírez Hurtado, L. (20I0). Imágenes del olvido, I9I4-1994. Discurso visual, manipulación y conmemoraciones de la Convención Revolucionaria de Aguascalientes. Aguascalientes: Universidad Autónoma de Aguascalientes. 
Reed, L., y Ruiz, M. (2002). El periodismo en México: 500 años de historia. México: EDAMEX.

Ross, S. (1965).El historiador y el periodismo mexicano. Historia Mexicana xiv (3), 347-382

Salmerón, P. (2006). La División del Norte: la tierra, los hombres y la historia de un ejército del pueblo. México: Planeta.

Sánchez Lamego, M. (1983). Historia militar de la revolución en la época de la Convención. México: INEHRM.

The Mexican Herald. (19I5, 8 de junio).

Ugarte, J. (I9I7). Impresiones de guerra. Breve relato de los acontecimientos políticos mexicanos comprendidos entre el mes de septiembre y el de noviembre de 19I4. San José: s/e.

Zuaste, R. (1992). El carrancismo a través de El Pueblo, I9I4-I9I9 [tesis de Licenciatura en Ciencias de la Comunicación]. Universidad Nacional Autónoma de México, Ciudad de México.

Este artículo se publica bajo una licencia de Creative Commons Reconocimiento-NoComercial 4.0
Internacional, y puede ser usados gratuitamente para fines no comerciales, dando los créditos a los
autores y a la revista.

